\title{
Personalized information spaces: improved access to chemical digital libraries
}

\author{
O Koepler*, W-T Balke, B Köhncke, I Sens, S Tönnies \\ From 5th German Conference on Cheminformatics: 23. CIC-Workshop \\ Goslar, Germany. 8-10 November 2009
}

Today digital libraries provide access to a vast, but largely unstructured, amount of document collections. Facing the ever increasing challenge of the information overload content providers have to focus on new ways in user-centered retrieval, not only providing tools for searching information, but tools for personalizing, managing, evaluating and working with the returned search results.

Within the ViFaChem II research project the TIB and the L3S Research Center, Hannover, have developed an enhanced retrieval platform for chemical digital libraries.

The prototypical interface processes full text and bibliographic metadata collections to create semantically enriched document collections with chemical metadata. Processing steps include text mining for chemical entities, reaction types and chemical structure reconstruction. However, the ViFaChem digital library does not only offer the classical document access via a text or chemical structure search, but also semantic search based on the faceted browsing paradigm. In particular it includes the Semantic GrowBag algorithm, which automatically creates facets for navigational access and query refinement using the relationship between documents and author keywords. Based on higher-order co-occurrences of keywords in documents these graphs hierarchically arrange all related topics dynamically with respect to the underlying content collection. Having different personal views on the document collection the user now can search and navigate through search results using individual retrieval strategies. Facets for chemical reactions, chemical entities or topics combined with an underlying ontology thus allow a semantic driven access to documents.

Combined with Web 2.0 features the interface of $\mathrm{ViFaChem} \mathrm{II} \mathrm{provides} \mathrm{the} \mathrm{user} \mathrm{with} \mathrm{a} \mathrm{new} \mathrm{experience} \mathrm{in}$

Technische Informationsbibliothek Hannover (TIB), Welfengarten,1B, 30167 Hannover, Germany searching large document collections, where the user can navigate through query results based on his personalized knowledge space.

Published: 4 May 2010

doi:10.1186/1758-2946-2-S1-018

Cite this article as: Koepler et al:: Personalized information spaces: improved access to chemical digital libraries. Journal of Cheminformatics 2010 2(Suppl 1):018.

\footnotetext{
Publish with ChemistryCentral and every scientist can read your work free of charge

"Open access provides opportunities to our colleagues in other parts of the globe, by allowing anyone to view the content free of charge." W. Jeffery Hurst, The Hershey Company.

- available free of charge to the entire scientific community

- peer reviewed and published immediately upon acceptance

- cited in PubMed and archived on PubMed Central

- yours - you keep the copyright

Submit your manuscript here:

http://www.chemistrycentral.com/manuscript/

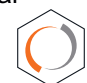
Chemistry Central
} 